\title{
Stroke Becomes the 3rd Important Cause of Death in Korea; Is It a Time to Toast?
}

\author{
Jong S. Kim \\ Editor-in-Chief, Journal of Stroke
}

Aside from cancer, stroke has long been the number one cause of death in Korea, followed by heart disease. Last year, our government reported that this order was reversed, due primarily to a decrease in stroke mortality (Figure 1). The change is striking; ten years ago (in 2002), stroke mortality was about two times higher than that of heart disease ( 77 per 100,000 vs. 36.9 per 100,000 , respectively) while in 2012 , the mortality rate due to heart disease and stroke was 52.5 and 51.1 per 100,000 people, respectively.

One of the important reasons for the rapid decline in stroke mortality is the improved quality of stroke care during the last 10 years; public awareness of stroke symptoms improved, the proportion of patients visiting hospitals within 3 hours increased, and door to needle time shortened, ${ }^{1}$ due in part to the widespread use of a computerized in-hospital alert system. ${ }^{2}$ Accord-

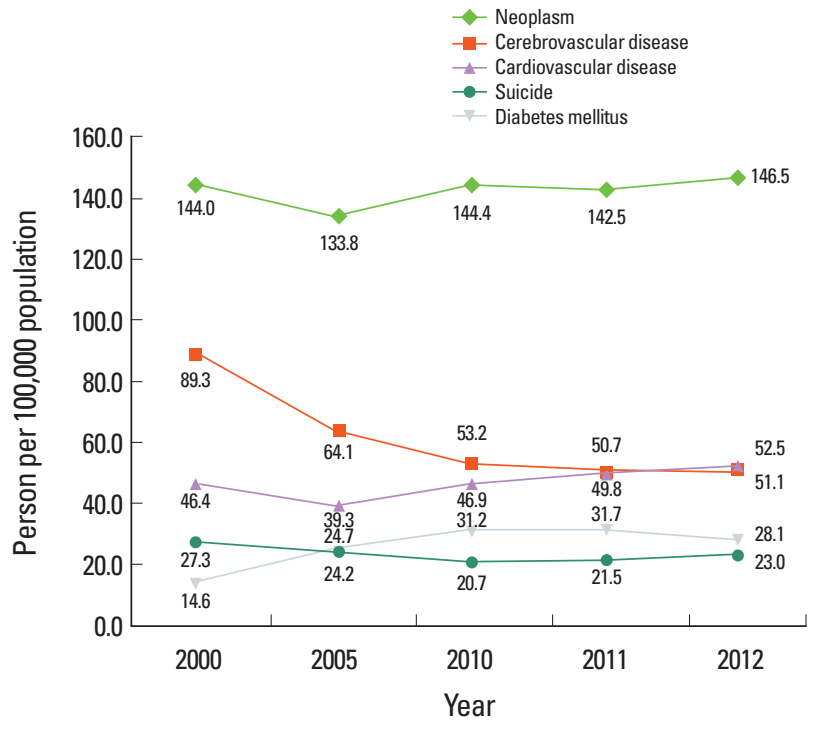

Figure 1. Secular trend of mortality associated with major diseases in Korea. ingly, the rt-PA treatment rate increased from $4.6 \%$ in 2005 to $7.9 \%$ in 2010 . The proportion of hospitals equipped with a qualified stroke unit has also increased from $1.1 \%$ in 2005 to $19.4 \%$ in $2010 .^{1}$

Another reason for this trend may be the fact that stroke has become a less dangerous disease in Korea. Hemorrhagic strokes, which are associated with high mortality, have been steadily declining, from $35.3 \%$ in 2000 to $23.9 \%$ in 2009 , probably in association with improved control of hypertension. ${ }^{3}$ Moreover, many aneurysms are now detected at routine health check-ups and treated before rupturing. For these reasons, the stroke fatality rate in Korea is now one of the lowest among OECD countries. ${ }^{3}$ Whatever the reason, the declining stroke mortality merits congratulation. However, it may not be good news.

Due to improved stroke care, and changing stroke subtypes, stroke fatalities have decreased. However, this paradoxically increases the number of stroke survivors. Stroke survivors need long-term preventive medicine, including antiplatelets, anticoagulants, or statins. Risk factors must be strictly managed and in some patients, operative therapies (such as carotid endarterectomy or stenting) are needed. These treatments are costly. Although hemorrhagic strokes are more costly in the acute stage, long-term care is significantly more expensive for secondary prevention of ischemic stroke. ${ }^{4}$ Furthermore, stroke survivors, especially those who develop recurrent strokes, are often disabled, depressed, and cognitively impaired. They significantly increase caregiver burden, and labor power will be lost from not only patients but also their caregivers.

In short, stroke has changed from a devastating fatal disease to a manageable illness requiring long-term, costly care. With accumulating stroke survivors, individual and social burdens will skyrocket. More importantly, despite the relatively improved 
risk factor control, there is no evidence of decreasing incidence of stroke in Korea, probably related with a rapidly increasing aged population. In this sense, stroke's stepping down to the $3 \mathrm{rd}$ most prominent cause of death is not news to toast. In fact, more research should be conducted to find ways to ameliorate the ever-increasing burden of stroke, both from academia and the government.

The recent changes shown in Korea have already been observed in Japan, and are currently shared by many other Asian countries such as urban China, Taiwan, and Hong Kong, as introduced in the recent editions of the Journal of Stroke (JOS). I believe that it is time to focus more on primary prevention by promoting healthy life style changes, (e.g., low salt intake, regular physical exercise, and stopping smoking). This will help decrease stroke incidence and unacceptably high stroke burden in Asia. Needless to say, Asian governments should play a bigger role than before.

One of the missions of JOS is to address these Asian issues worldwide. In this volume, you can read with interest about stroke epidemiology in Taiwan, genetic abnormalities in moyamoya disease, and an argument that new oral anticoagulants may be particularly useful for Asian stroke patients, on which Dr. Diener kindly sent his comments. I hope you enjoy reading them.

\section{References}

1. Hong KS, Bang OY, Kim JS, Heo JH, Yu KH, Bae HJ, et al. Stroke statistics in korea: Part ii stroke awareness and acute stroke care, a report from the korean stroke society and clinical research center for stroke. J Stroke 2013;15:67-77.

2. Heo JH, Kim YD, Nam HS, Hong KS, Ahn SH, Cho HJ, et al. A computerized in-hospital alert system for thrombolysis in acute stroke. Stroke 2010;41:1978-1983.

3. Hong KS, Bang OY, Kang DW, Yu KH, Bae HJ, Lee JS, et al. Stroke statistics in Korea: Part i. Epidemiology and risk factors: a report from the korean stroke society and clinical research center for stroke. J Stroke 2013;15:2-20.

4. Rha JH, Koo J, Cho KH, Kim EG, Oh GS, Lee SJ, et al. Twoyear direct medical costs of stroke in korea: a multi-centre incidence-based study from hospital perspectives. Int J Stroke 2013;8:186-192.

Correspondence: Jong S. Kim

Department of Neurology, Asan Medical Center, University of Ulsan

College of Medicine, 88 Olympic-ro 43-gil, Songpa-gu,

Seoul 138-736, Korea

Tel: +82-2-3010-3442, Fax: +82-2- 474-4691

E-mail: jongskim@amc.seoul.kr 